\title{
INSTITUIÇÕES FINANCEIRAS SOB UMA ANÁLISE FUNCIONAL
}

ISTITUZIONI FINANZIARIE SOTTO ANALISI FUNZIONALE

\author{
${ }^{1}$ Eduardo Francisco de Souza \\ ${ }^{2}$ Bruno Henrique Tenório Taveira
}

\section{RESUMO}

O presente trabalha se vale da obra de Norberto Bobbio na tentativa de proceder a uma análise funcional do sistema financeiro e das instituições financeiras. A perspectiva funcionalista orienta uma crítica ao papel que as instituições financeiras assumiram num contexto de crise econômica cujas origens estão, segundo autores, na forte desregulação financeira e no seu descasamento do setor produtivo. No cenário nacional, a perspectiva funcionalista apresentada possibilita uma crítica ao manejo disfuncional das instituições públicas de fomento (sobretudo, o BNDES), propiciadas pelo sigilo bancário, bem como se cogita de uma função negativa de tais instituições, derivada da solução proposta para essa mencionada disfuncionalidade afastamento irrestrito do sigilo bancário em operações conduzidas por bancos públicos de fomento.

Palavras-chave: Instituições financeiras, Funções, Bndes, Sigilo bancário

\begin{abstract}
Questo lavoro, sulla base di studi di Norberto Bobbio, prova di effettuare un'analisi funzionale del sistema finanziario e le istituzioni finanziarie. La prospettiva funzionalista dirige una critica del ruolo che le istituzioni finanziarie hanno preso in un contesto di crisi economica le cui origini sono, secondo alcuni autori, la forte deregolamentazione finanziaria e il suo distacco del settore produttivo. Sulla scena nazionale, la prospettiva funzionalista presentato permette una critica della gestione disfunzionale delle istituzioni pubbliche per lo sviluppo (la banca notta come BNDES), offerti dalla segreto bancario, e si sta valutando una funzione negativa di tali istituzioni, derivato dalla soluzione proposta fronte questa menzionata disfunzionalità rimozione senza restrizioni del segreto bancario in operazioni condotte dalle banche di sviluppo pubbliche.
\end{abstract}

Keywords: Instituizioni finanziarie, Funzioni, Bndes, Segreto bancario

\footnotetext{
${ }^{1}$ Mestrando em Direito Comercial pela Universidade de São Paulo - USP, São Paulo, SP, (Brasil). Justica Federal de Primeiro Grau no Rio de Janeiro - Secão Judiciaria do RJ, JF/SECAO RJ,Rio de Janeiro.E-mail.: eduardofcosouza@hotmail.com

${ }^{2}$ Mestrando em Justiça Administrativa na Universidade Federal Fluminense - UFF, Rio de Janeiro, RJ, (Brasil). Juiz de Direito do Tribunal de Justiça do Estado de Minas Gerais, TJMG, Minas Gerais, MG.(Brasil). E-mail.: bruno.taveira@hotmail.com
} 


\section{O DIREITO SOB UMA PERSPECTIVA FUNCIONALISTA}

Na década de 70, do último século, o jusfilósofo Norberto Bobbio publicou uma série de estudos, reunidos num livro denominado "Dalla struttura alla funzione: nuovi studi di teoria del diritto", defendendo a importância da perspectiva funcionalista no campo jurídico.

Embora não seja um trabalho comumente relacionado aos estudos do movimento Law and Economics, vislumbra-se ao longo do referido texto a presença de preocupações que claramente aproximam o jurista dos problemas econômicos da sociedade contemporânea.

No estudo denominado "Verso una teoria funzionalistica del diritto", Bobbio (1977, p. 63-88) apresenta a diferença entre a perspectiva estruturalista e a funcionalista. Em linhas gerais, a primeira, predominante na ciência jurídica, compreende o direito a partir de suas estruturas, privilegiando como o perfil interno das normas jurídicas se delineia, e como elas se relacionam na composição do ordenamento jurídico.

Do ponto de vista funcional, o estudioso do direito levaria em consideração a teleologia das normas, ou as finalidades as quais procuram (as normas) atenderem. Ao invés de se preocupar apenas com o "como", o jurista deve considerar na sua atividade o "para que" da norma.

Evidentemente, a perspectiva funcional ao incorporar no mundo jurídico finalidades sociais e econômicas não implica desconsiderar as tradicionais preocupações atinentes à perspectiva estrutural. Essa diferença é exemplificada por Bobbio (1977, p. 64) quando este se reporta ao grande expoente da perspectiva estrutural, francamente dominante na seara jurídica, o austríaco Hans Kelsen.

Com efeito, segundo Bobbio, Kelsen em sua "Reine Rechtsteorie", sobretudo na primeira edição, disse que o direito enquanto estrutura atende uma finalidade, mas que essa finalidade não seria objeto da teoria pura do direito. $O$ jurista kelseniano sabe que as estruturas jurídicas tem uma finalidade, mas ele não deve se interessar por ela, pois do contrário não estaria mais na pura ciência jurídica, e sim em outro terreno como a política ou a economia.

Bobbio (1977), por sua vez, diz que a perspectiva funcionalista não desconhece a importância das estruturas normativas, porém rejeita que tais estruturas tenham uma função natural, a ela inerente, ou seja, uma estrutura que atenda a uma e somente a uma finalidade. $\mathrm{O}$ saber jurídico poderia cogitar não apenas uma função inerente a uma dada estrutura, como 
também reconhecer a possibilidade de se lhe agregar funções outras, e que essa faceta não é externa à ciência jurídica. Em suas palavras:

\begin{abstract}
Kelsen non cadde nell 'errore di Stammler, che provocò un critica piuttosto severa di Max Weber, di confondere lanalisi formale del diritto come premessa per una teoria scientifica e compiutamente de-ideologizzata del diritto, con la concezione del diritto come forma di rapporti sociali, in particolare dei raporti economici. Bisogna pur riconoscere che altro è dire che il diritto como ordinamento normativo ha una sua struttura, che è compito della teoria generale del diritto d'individuare e descrivere, altro è dire che il diritto è e non è altro che una struttura dei raportti sociali. La prima concezione se limita a separare l’analisi strutturale da quela funzionale considerando soltanto la prima come oggeto di una teoria pura del diritto. La seconda non può concepire un`analise funzionale distinta di quella strutturale per il semplice fatto che confonde la struttura con la funzione, e sostiene che il diritto ha una funzione in quanto è una struttura dei rapporti sociali. (BOBBIO, 1977, p. 66)
\end{abstract}

O valor desta senda teórica, que nega ao jurista um absenteísmo com a dimensão teleológica da norma e do ordenamento, deve ser reconhecido, sobretudo quando se está diante do Direito Comercial, historicamente comprometido com o modo pela qual as diversas sociedades se organizam para produzir bens destinados a atender suas necessidades. Na visão de Ascarelli (2007, p. 24), contrapondo-se ao direito comum, o Direito Comercial elaborou os institutos mais típicos da economia moderna, aqueles que constituem quase que os instrumentos jurídicos desta, a exemplo das sociedades anônimas, dos títulos de crédito e do seguro.

O Direito Comercial, quiçá como nenhum outro, é a prova inconteste do direito que conforma uma realidade e é, ao mesmo tempo, por ela é conformado. Desde o seu surgimento, relacionado aos afazeres dos mercadores medievais, as normas comerciais atendiam às necessidades destes últimos. Sem prejuízo da crítica classista que lhe era dirigida, o direito mercantil marcou a evolução a partir de sucessivas reformulações (do ato de comércio à empresa), sempre tendo como ambiente as transformações econômicas pelas quais a sociedade passou ao longo dos tempos. Neste particular, Forgioni (2012, p. 27) identifica o mercado como objeto do Direito Comercial, cabendo a este a formatação jurídica daquele.

A visão jurídica do mercado, aliás, fica facilitada com a perspectiva funcionalista, mormente quando se cogita de particulares problemas como desvirtuamento das instituições jurídicas. Para além da já tradicional abordagem muito comum entre os civilistas, do abuso do direito, Bobbio (1977) chega a discutir o conceito de disfuncionalidade, no plano da teoria geral do direito, distinguindo-o da ideia de função negativa. Um instituto pode ter uma função positiva ou negativa, sendo que esta última não se confunde com a disfunção. A disfunção 
está relacionada a uma patologia da função, enquanto a função positiva diz respeito à fisiologia (BOBBIO, 1977, p. 100).

Dentro dessas linhas teóricas, é que se pode analisar a relevante função dos bancos ou, mais genericamente, das instituições financeiras para a economia, sob a ótica jurídica. Tais agentes econômicos compõem o que se denomina mercado financeiro, cujo papel é objeto de relevante debate especialmente nos tempos atuais, em que, segundo economistas, recentes crises econômicas têm sua origem no setor das finanças, com impactos evidentes e pungentes sobre a vida de pessoas e empresas.

Não é incomum a associação entre a última grande crise econômica, cujo epicentro estaria na atuação de agentes financeiros que operavam no ramo imobiliário dos Estados Unidos da América, a supostas disfuncionalidades da regulação financeira, ou mesmo carência desta última. A crítica subjacente é que as instituições financeiras em especial os bancos não mais estariam cumprindo a função pela qual foram concebidos, e ao Estado, tanto em nível político, quanto em nível jurídico, caberia operacionalizar regras formais ou instituições destinadas a corrigir os rumos do mercado financeiro.

Essa orientação é privilegiada pela perspectiva funcionalista do direito, pois esta última vislumbra instrumentos específicos como a chamada sanção premial e os incentivos. A norma jurídica ao coligar a um comportamento uma certa consequência, diz que esta última nem sempre será alguma repreensão ou resultado de cunho negativo, podendo se tratar de uma sanção positiva, que represente um prêmio pelo comportamento querido pela norma, ou mesmo um incentivo ao comportamento prescrito. Ressalte-se, aliás, que é justamente com incentivos, por exemplo, que a economia trabalha, estando aqui mais uma razão para a compreensão aproximada entre direito e economia.

O presente trabalho, portanto, tem a pretensão de traçar uma crítica a uma orientação excessivamente empoderada do mercado financeiro, a partir de uma visão dos bancos públicos de desenvolvimento, cuja função deveria ser reafirmada, ou não, visando verificar se a instituição do sigilo bancário disfuncionaliza ou funcionaliza negativamente a atuação dos bancos públicos, em especial o Banco Nacional de Desenvolvimento Econômico e Social (BNDES).

\section{SISTEMA ECONÔMICO E SISTEMA FINANCEIRO: DIFERENCIAÇÃO}


O entendimento da problemática acima apresentada passa por uma distinção inicial entre o que seria econômico e o que seria financeiro. Tais termos frequentemente são utilizados de forma indistinta, sendo certo que a compreensão das suas diferenças é importante para acompanhamento das questões colocadas neste trabalho.

Tendo em vista as limitações do presente texto, passa-se deliberadamente ao largo da construção do conceito de sistema, e sua introdução no pensamento jurídico. Para nossos fins, na lição de Sztajn (2011, p. 37-44), com base nas lições de Nikklas Luhman, o sistema é uma classificação dentro de uma estrutura que permite associar e/ou separar unidades em função de semelhanças ou diferenças em arranjos hierárquicos ou funcionais, diferenciando-se, a partir da noção sistema/ambiente, sistemas abertos ou fechados, conforme interajam ou não com o entorno, sendo os abertos sistemas naturalmente complexos.

Assim, visto que não se fala em sistema, e sim em sistemas, pode-se construir uma tipologia que diferencie o econômico do financeiro. Embora ambos estejam relacionados a riquezas, não se confundem.

\footnotetext{
O sistema econômico, o mais antigo, estuda a produção, a circulação, o consumo de bens e serviços, e as relações entre essas atividades na sociedade. Esse sistema é composto por pessoas e instituições, e tem como objeto o estudo da relação das pessoas e instituições com a alocação de recursos produtivos.

O sistema financeiro, mais recente, relaciona fatores como moeda, tempo e risco. Este sistema reúne instituições que atuam na emissão da moeda, na sua circulação e concessão de crédito, na transformação de riscos (SZTAJN, 2011, p. 45).
}

Quanto ao sistema financeiro, em que se destacam as instituições financeiras objeto do presente trabalho, o elemento unificador do sistema é o fato de que as prestações de ambas as partes são denominadas em moeda (SZTAJN, 2011, p. 137).

A compreensão do que seja moeda, apesar de relacionar elementos jurídicos, tradicionalmente não faz parte do campo das preocupações do jurista. Assim, diversas concepções partem de conceitos jurídicos para explicar o surgimento e o funcionamento da moeda. Metri (2014) apresenta duas vertentes teóricas que pretendem explicar o que seja moeda: Para Alfred Mitchel Innes, a essência de uma transação econômica são as relações de débito-crédito, sendo que moedas nada mais são que créditos que podem ser acumulados ou usados para compensar obrigações emitidas, ou ainda, servir para aquisição de algum bem ou serviço. Por sua vez, para Georg Friedrich Kanapp, o decisivo para criação de uma moeda é a capacidade de uma autoridade política impor a condição de devedor de tributos ao conjunto da coletividade sobre o qual aquela autoridade exerce poder e dominação.Vê-se, portanto, 
que ambas as teorias acima partem de elementos jurídicos, a primeira manuseando categorias de direito privado (crédito/débito) enquanto a segunda, de direito público (soberania/império) para conceituar moeda.

A par da dificuldade de se definir moeda, e para compreender as funções das instituições financeiras, é útil entender as funções da moeda. Sztajn (2011, p. 20-25) ensina que a moeda tem pelo menos três significativas funções: meio de troca (poder liberatório), unidade de conta (precificação) e reserva de valor (preservação do poder de compra).

Meio de pagamento porque a moeda opera como bem intermediário de troca, reduzindo custos da transação, em razão de uma particular característica sua: fungibilidade. $\mathrm{Na}$ função de unidade de conta, se destacam o elemento fungibilidade e o fracionamento da moeda, que permitem a precificação de bens e serviços negociados no mercado, bem como a concessão de empréstimos, os quais podem ser remunerados ao longo do tempo, através dos juros. Essa última é muito próxima à terceira função da moeda, como reserva de valor, pois a moeda pressupõe a estabilidade do poder de compra e, sobretudo, a confiabilidade que inspira em seus detentores, no sentido de que não perderá qualidade com o passar do tempo.

Observa-se, portanto, que o sistema financeiro apresenta espectro limitado, estando essencialmente ligado à instituição monetária, o que, por evidente, não esgota o amplo campo de análise da economia. O estudo da história permite aclarar bem a distinção entre tais sistemas, bem como assinalar a instrumentalidade de um em relação a outro. De fato, a origem histórica dos bancos refletiria a instrumentalidade do financeiro em favor do econômico. O "mercador-banqueiro" medieval atuava no financiamento do comércio marítimo, destacando-se os florentinos, especialmente a Casa dos Médicis, portando-se, segundo Le Goff (1991, p. 21-26), como verdadeiros capitalistas.

Calha dizer que essa instrumentalidade, aliás, tem esteio jurídico, inclusive, na nossa ordem constitucional, pois o art. 192, da CF, é claro ao apontar a teleologia que deve nortear as finanças, valendo-se ademais do termo "sistema financeiro": "O sistema financeiro nacional, estruturado de forma a promover o desenvolvimento equilibrado do País e a servir aos interesses da coletividade(...)”.

É fato que o curso da história e da criatividade humana logrou assinalar outros fins a que as instituições financeiras deveriam perseguir. No entanto, mormente quando há uma norma jurídica de matiz constitucional assim direcionando, a tradicional e longeva função deve ser prestigiada. Assim, nos parece que só em sentido metafórico poder-se-ia falar em indústria financeira, até porque os produtos que esta "indústria" (NUNES, 2012, p. 28) produz 
não passam de serviços, cuja relevância está condicionada a sua utilidade na promoção, incentivo e financiamento de outras atividades humanas, essas sim que satisfazem as necessidades humanas.

Nesse sentido, recente estudo conduzido na Organização para Cooperação e Desenvolvimento (OECD, 2015) aponta que o crescimento descontrolado do setor financeiro é maléfico para a economia mundial, alertando, por exemplo, que, no ritmo atual do financiamento do desenvolvimento, a expansão da oferta de crédito bancário ao sector privado irá resultar em um crescimento mais lento na maioria dos países da OCDE. Um aumento do crédito bancário de $10 \%$ do PIB levaria a uma queda de 0,3 ponto no crescimento do PIB, de acordo com a OCDE.

\section{FUNÇÕES DAS INSTITUIÇÕES FINANCEIRAS NO DIREITO BRASILEIRO}

O estudo das funções das instituições financeiras deve ser precedido pelo tormentoso problema da definição do que seja instituição financeira. No Brasil, inclusive em descompasso com o conselho segundo o qual a lei não deve se preocupar em definir conceitos, a legislação conceituou instituição financeira, nos seguintes termos:

Art. 17. Consideram-se instituições financeiras, para os efeitos da legislação em vigor, as pessoas jurídicas públicas ou privadas, que tenham como atividade principal ou acessória a coleta, intermediação ou aplicação de recursos financeiros próprios ou de terceiros, em moeda nacional ou estrangeira, e a custódia de valor de propriedade de terceiros (LEI N 4.595, DE 31 DE DEZEMBRO DE 1964).

Talvez o adágio acima citado seja confirmado pelo art. 17 da lei 4.595, de 1964, visto que é curioso que, constando de uma definição legal, o que em tese contribuiria para lhe garantir certeza jurídica, pelo contrário, trouxe espinhosa controvérsia, sendo justamente uma das grandes fontes de discórdias no direito bancário, refletindo, aqui, o que ocorre alhures.

De forma sintética, pode-se dizer que o conceito de instituição financeira pode variar conforme se adote ou não uma visão cumulativa dos requisitos elencados no dispositivo legal. Segundo explica Salomão Neto (2005, p. 27), a aplicação literal da definição constante na lei implicaria alargar em excesso o conceito de instituição financeira, pugnando por uma interpretação teleológica do dispositivo. O próprio autor, no entanto, reconhece que há forte tendência doutrinária que defende a interpretação literal do dispositivo, de modo a abranger no conceito de instituição financeira o máximo possível da realidade econômica. 
Dessa discussão pode-se concluir que a funcionalidade das instituições financeiras poderá estar associada com a vertente conceitual que se adote. De fato, entende-se pela cumulação de requisitos legais de "captação, intermediação ou aplicação", opera-se uma restrição conceitual, que condiz com uma função histórica do banco, a seguir examinada, tradicional modalidade de instituição financeira. Por outro lado, optando-se pela não cumulação se potencializa a noção de instituição financeira, destacando mais o aspecto “autorização" pelo poder público.

Como mencionado em linhas anteriores deste trabalho, pode-se dizer que a função precípua das instituições financeiras é intermediar recursos financeiros entre agentes econômicos. As instituições financeiras procedem a uma intermediação indireta entre o poupador e o tomador de recursos, diferenciando-se do mercado de capitais, que proporciona um contato imediato entre aqueles dois agentes. A instituição financeira intermedeia mediante a "transmutação dos recursos", ou seja, capta recurso atrelado a um perfil específico de poupador e aplica ou investe em operação com perfil distinto, por exemplo, os recursos depositados pelas famílias em cadernetas de poupança são utilizados no financiamento do crédito imobiliário. Consigne-se que se faz a transmutação de recursos ao mesmo tempo em que se trabalha o risco (transferindo para quem estiver melhor posicionado para suportá-lo), sendo a instituição financeira remunerada pela assunção de riscos (PINHEIRO; SADDI, 2005, p. 434-442).

Essa seria a essência da atuação financeira. O modo como ela cumpre sua função é evidenciado através das mais diversas operações, as quais são estruturadas de forma a garantir a maior segurança jurídica possível aos agentes. A estruturação de tais operações, e a correta percepção do seu espírito pelo Judiciário, é fator de redução de incertezas, e implica eficiência no mercado, traduzida, por exemplo, em juros de longo prazo menores (BACHA; ARIDA; REZENDE, 2012, p. 214). O estudo de tais operações, ainda que de forma introdutória, é importante na esteira do que restou antes consignado no sentido de que a perspectiva funcional não implica desprezo pelas estruturas jurídicas.

\section{OPERAÇÕES BANCÁRIAS}

A influência da economia sobre o direito que disciplina o mercado financeiro pode ser sentida já em nível terminológico, pois de há muito se fala com mais fluidez, mesmo entre profissionais do direito, em operações bancárias. O termo "operações" é consagrado pela tradição, e mesmo pelos antecedentes legislativos (art. 119, do Código 
Comercial/Regulamento n. 737/1850). Com isso, ressalta-se o aspecto econômico do negócio jurídico (ABRÃO, 2000, p. 42).

A dogmática jurídica tradicionalmente classifica as operações em duas espécies. As operações passivas são aquelas nas quais as instituições financeiras assumem a posição de devedor enquanto nas operações ativas as instituições financeiras assumem posição de credor. Pode-se relacionar o seguinte rol de umas e outras:

Operações ativas:

- Abertura de crédito, simples e em conta-corrente;

- Desconto de títulos;

- Concessão de crédito rural;

- $\quad$ Concessão de empréstimo para capital de giro;

- $\quad$ Aplicações (próprias) em títulos e valores mobiliários;

- Depósitos interfinanceiros;

- Operações de repasses e refinanciamentos

- Concessões de financiamentos de projetos do Programa de Fomento à Competitividade Industrial.

Operações passivas:

- $\quad$ Depósitos a vista (de pessoas físicas ou jurídicas);

- Depósitos a prazo fixo (de pessoas físicas ou jurídicas);

- Obrigações contraídas no país e no exterior relativas a repasses e refinanciamentos;

- $\quad$ Emissões de certificados de Depósitos Interfinanceiros (CDIs).

Para os fins do presente trabalho, interessa menos o aprofundamento em cada uma destas operações, e mais o liame entre elas, que viabiliza a funcionalidade das instituições financeiras. Com efeito, a tradicional doutrina, por todos, Abrão (2000, p. 42), tem acentuado a interdependência de tais operações, pois a partir de uma coligação entre operações passivas e ativas se possibilitam efeitos jurídicos e econômicos que não seriam cogitáveis se as operações fossem avulsas.

Essa noção, aliás, é útil para entender que a atividade financeira deve ser sempre analisada em seu conjunto, ante a complexidade que norteia o entrelaçamento das mais diversas operações levadas a cabo pelas instituições financeiras, o qual define o sucesso ou insucesso da atividade financeira. Daí que não se pode analisar uma operação negligenciando uma compreensão consequencialista, pois determinada operação nunca surge de forma 
isolada, e sim está inserida num contexto de interdependência, cujas consequências são sentidas em todo o arranjo. As decisões judiciais não podem perder de vista essa dimensão sistêmica que permeia a estrutura e o funcionamento das instituições financeiras.

Por outro lado, e não se pode deixar de pontuar que nenhuma classificação é certa ou errada, e sim atende ou não a uma determinada finalidade, a compreensão das diversas espécies de operações é importante para a determinação da tipologia das instituições financeiras. Deveras, a classificação acima apontada é útil para construção de outra classificação importante, consistente na tipologia das instituições financeiras.

Como se sabe, a doutrina elenca diversas espécies de instituições financeiras, sendo certo que o critério diferenciador reside justamente na operação ativa preponderante. Ao se concentrar em uma determinada operação, a instituição financeira atua mediante relacionamentos contratuais de forma especializada, afigurando-se útil na compreensão desta série de contratos a noção de causa contratual. Sem embargo de grande polêmica em torno da causa do contrato no Direito Civil, para o Direito Comercial a ideia de causa, segundo Forgioni (2008, p. 525-527) padece de maiores dificuldades, vez que é compreendida como a própria "função econômica do contrato", ou o fim prático do contrato, diferenciando-se dos motivos, que teriam um caráter subjetivo.

Forte nas lições de Ascarelli, para quem a noção de causa constitui um traço de união entre o aspecto jurídico e o econômico, Forgioni (2008, p. 529) ensina que a causa coliga o negócio ao mercado, à praça onde nasce, desenvolve-se e se exaure, permitindo o cálculo do comportamento da outra parte, podendo a ela (causa) ser atribuída diversos papéis, dentre os quais, ser elemento de qualificação.

Nesse passo, em atendimento a ideia de causa como elemento de qualificação jurídica, a doutrina ${ }^{1}$ relaciona as espécies de instituições financeiras, conforme a operação preponderante.

\footnotetext{
1 A legislação traz uma classificação própria no art. 18, parágrafo único, da Lei n. 4.595/64: Art. 18. As instituições financeiras somente poderão funcionar no País mediante prévia autorização do Banco Central da República do Brasil ou decreto do Poder Executivo, quando forem estrangeiras.

$\S 1^{\circ}$ Além dos estabelecimentos bancários oficiais ou privados, das sociedades de crédito, financiamento e investimentos, das caixas econômicas e das cooperativas de crédito ou a seção de crédito das cooperativas que a tenham, também se subordinam às disposições e disciplina desta lei no que for aplicável, as bolsas de valores, companhias de seguros e de capitalização, as sociedades que efetuam distribuição de prêmios em imóveis, mercadorias ou dinheiro, mediante sorteio de títulos de sua emissão ou por qualquer forma, e as pessoas físicas ou jurídicas que exerçam, por conta própria ou de terceiros, atividade relacionada com a compra e venda de ações e outros quaisquer títulos, realizando nos mercados financeiros e de capitais operações ou serviços de natureza dos executados pelas instituições financeiras.
} 
A despeito de respeitáveis entendimentos em sentido contrário, tal como exposto por Verçosa (2010, p. 195-200) sobre a inutilidade do conceito, o qual se confundiria com o próprio objeto do contrato, a ideia de causa, notadamente quando entendida como função econômica do contrato, representa um importante instrumento para que o intérprete compreenda a vontade comum das partes quando da contratação, quais os fins a que a relação contratual almejava, aproximando, portanto, os juristas da realidade econômica subjacente ao contrato.

A. Bancos. Instituições tradicionais voltadas ao financiamento geral das atividades econômicas, sem necessidade de especialização em certo tipo de atividade ativa. Podem ser subdivididos em três tipos: 1) bancos comerciais, cuja atividade preponderante é o financiamento a curto e médio prazo o comércio, a indústria e as empresas prestadoras de serviço, apresentando algumas restrições quanto à forma de captação; 2) bancos de investimento, cuja atividade preponderante é o investimento, a participação ou o financiamento a prazos médio e longo, para suprimento de capital fixo ou de movimento de empresas do setor privado; e, por fim, 3) bancos de desenvolvimento: sendo preponderante o financiamento, a médio e longo prazos, de programas e projetos que visem promover desenvolvimento econômico e social da comunidade.

B. Sociedades de Créditos, Financiamento e Investimento: especializam na captação para financiamento de aquisição de bens e serviços e para capital de giro.

\section{Sociedade de Crédito Imobiliário e Companhias Hipotecárias:} especializadas na captação para financiamento imobiliário.

D. Cooperativas de Crédito: tem por objeto a cooperação mútua dos seus associados através de economia sistemática e de uso adequado do crédito.

E. Instituição Financeiras Públicas: assumindo diversas, como autarquias, empresas públicas ou sociedades de economia mista, destacando-se o Banco Nacional de Desenvolvimento Econômico e Social (BNDES). 


\section{DESVIRTUAMENTO FUNCIONAL DAS INSTITUIÇÕES FINANCEIRAS?}

No espectro político, tem-se acentuado uma forte crítica à atuação das instituições financeiras a nível global. Na cena política americana, por exemplo, destacou-se o ativismo da Professora de Direito Comercial e atual senadora Elizabeth Warren, que tem produzido fortes críticas contra uma complacência do governo para com os chamados grandes demais para falir, que receberiam inclusive subsídios governamentais.

Em nível global percebe-se um momento de endurecimento do poder estatal em face dos grandes conglomerados bancários, seara em que os Estados Unidos da América também se destacam, podendo-se citar algumas investigações conduzidas pelo Departamento de Justiça daquele país, que resultaram inclusive em substanciais multas contra instituições financeiras, a exemplo do BNP Paribas, este último inclusive gerando ruídos diplomáticos com a França; o caso do HSBC que supostamente lavaria dinheiro oriundo do narcotráfico mexicano, ou mesmo a pressão do governo americano sobre o governo suíço no que diz respeito à imposição de limites ao sigilo fiscal, instituição que fez a fama da Suíça em termos de finanças.

Não se pode deixar de mencionar a edição do chamado acordo da Basiléia III, um conjunto de regras de tendência reformadora da regulamentação bancária mundial, de 16 de dezembro de 2010, promovido pelo Fórum de Estabilidade Financeira (em inglês, Financial Stability Board, FSB).

A par de alguns escândalos noticiados, como a manipulação da taxa interbancária Libor, em que foram flagrados funcionários de grandes bancas internacionais praticando atividades ilícitas, o fato é que a imagem dos bancos nunca esteve tão abalada como nos dias atuais, não sendo desprezível a importância assumida por fatores intangíveis, como a imagem, no segmento financeiro, onde a confiança é crucial para o giro dos negócios. A desconfortável posição assumida pelos bancos está em muito relacionada à grande crise financeira, advinda, segundo analistas, da frouxa regulação dos mercados financeiros.

A grande crise de 2007/2008, apesar de seus reflexos na economia como um todo, com desaparecimentos de postos de trabalhos, e o aniquilamento de empresas, teria se originado em disfuncionalidades das finanças mundiais. Em um primeiro momento, demonstraria os perigos inerentes à ascensão da indústria financeira, que, em movimento semelhante ao que foi a revolução industrial no século XIX, afirmou a proeminência de uma 
nova forma de capitalismo: o capitalismo financeiro. É essa a crítica de Galgano (2010), traduzida na contraposição entre a chamada economia financeira e a economia real. Nos períodos de crise, os investidores descobrem que a esperança de riqueza futura não se confirma, seja pela recessão na economia real seja porque a economia financeira se dilatou além de uma razoável previsão da futura riqueza real, ou mesmo porque a riqueza financeira se revela riqueza ilusória (GALGANO, 2010, p. 270).

$\mathrm{Na}$ base dessa grande crise, Faria (2009) aponta o descasamento funcional entre o setor financeiro e o produtivo:

\begin{abstract}
Combinando assim fatores novos e antigos, a crise de 2008 atingiu todos os mercados - do monetário ao de crédito, das bolsas de valores e de mercadorias às operações com opções de compra, contratos futuros e swaps, envolvendo até mesmo instituições não financeiras, como é o caso de companhias seguradoras e construtoras. Em vez de terem se expandido para financiar a produção, esses mercados cresceram em sentido inverso, acumulando ativos de qualidade duvidosa ao multiplicar operações especulativas e de curto prazo, em detrimento de investimentos produtivos de médio e longo prazos (FARIA, 2009, p. 301).
\end{abstract}

Segundo Nunes (2012, p.27), Keynes há mais de 50 anos já advertia para os perigos de paralisação da atividade produtiva em consequência do aumento da importância dos mercados financeiros e da finança especulativa. Para o professor da faculdade de direito de Coimbra, dentre as características do processo de globalização financeira, esta a chamada desintermediação, que se traduz na "perda de importância da tradicional intermediação da banca nos mecanismos de crédito" pois os grandes investidores institucionais, como os bancos e fundos de investimento, "tem acesso direto e em tempo real aos mercados financeiros de todo o mundo para colocação dos fundos disponíveis e obtenção de crédito" (NUNES, 2012, p. 26).

Explicações de viés regulatório foram vislumbradas por analistas. Assim por exemplo apontou-se o fim da cisão legal das atividades bancárias e de investimento propiciada, nos EUA, pela Lei Glass-Steagall, esta última advinda no contexto da crise de 1929. Por esta lei, uma instituição financeira não poderia operar serviços de banca comercial e de investimentos, cisão esta que proporcionaria uma alavancagem mais consistente com as necessidades das corporações industriais (setor não-monetário). Com o advento da lei Gramm-Leach-Bliley, de 1999, pôs-se fim a cisão das atividades bancárias e de investimentos. Estaria aí o ovo da serpente, as condições jurídicas que criaram o ambiente para a crise vinda menos de 10 anos depois ${ }^{2}$, muito embora haja quem opine, como Macey (2000, p. 721), que a lei se justificava, pois geraria benefícios competitivos substanciais à indústria de serviços financeiros dos Estados Unidos. 
Apontou-se ainda a proliferação de instrumentos financeiros que, estruturados sob uma regulação frouxa, alimentavam uma ciranda de negócios inconsistentes, os chamados derivativos.

Para Carvalho (1999), a origem dos derivativos está intimamente ligada à negociação de commodities, remontando à China antiga e à especialização do comércio na Idade Média. O seu aparecimento visava agilizar e dar maior segurança à negociação dessas mercadorias básicas. Possibilitava-se a antecipação de vendas, através de um contrato em que o produtor se comprometia a entregar futuramente determinada quantidade de mercadoria a determinado preço, garantindo-se ao produtor o escoamento de sua produção. Já para o comprador, o contrato derivativo significava a garantia de preço e a certeza do produto na quantidade, qualidade e local previam ente contratados. Após, surgem os derivativos destinados à proteção contra variações de taxas de juros ou de variações de moedas, ou seja, como forma de proteção a riscos (hedge).

Observa-se que tais instrumentos (derivativos) não são estruturalmente ilícitos. Foram eles inicialmente concebidos como instrumentos de proteção financeira contra instabilidades próprias do mercado. Sucede, entretanto, um manuseio disfuncional dos derivativos. Por motivos diversos, notadamente sob o signo do imediatismo do lucro rápido, incompatível com o investimento produtivo, tais derivativos passaram a satisfazer a ganância do capital especulativo, orientado pelo ideal de lucro máximo no menor prazo possível, o mercado financeiro desvirtua a causa de tais instrumentos jurídicos, atribuindo-lhe uma conotação de um negócio cujo fim imediato seria a especulação, e não com finalidade de proteção de capital, assemelhando-o a um contrato de aposta.

Atento a este desvirtuamento de um instrumento financeiro como indicativo do

\footnotetext{
2 Nesse sentido, recente artigo do Prof. Delfin Neto (2015), para quem "Todos sabemos que um eficiente e competitivo sistema financeiro é elemento essencial para mobilização das poupanças que financiam o investimento, alma do crescimento econômico. Tudo bem considerado, entretanto, foi visível até os anos 80 do século passado que, apesar de ter prevenido uma outra 'grande depressão', as restrições impostas pelo Act de 1933 não eliminaram a repetição dos 'ciclos de negócios' ínsitos na organização econômica das sociedades através dos "mercados" e não impediram um crescimento razoável.(...)

Todos sabemos que um eficiente e competitivo sistema financeiro é elemento essencial para mobilização das poupanças que financiam o investimento, alma do crescimento econômico. Tudo bem considerado, entretanto, foi visível até os anos 80 do século passado que, apesar de ter prevenido uma outra 'grande depressão', as restrições impostas pelo Act de 1933 não eliminaram a repetição dos 'ciclos de negócios' ínsitos na organização econômica das sociedades através dos “mercados" e não impediram um crescimento razoável."
} 
desvirtuamento funcional das próprias instituições financeiras, Menezes Cordeiro (2014, p.

134) assinala que:

\begin{abstract}
A liquidez abundante e a possibilidade de conseguir lucros extraordinários no mercado da bolsa e no setor de derivativos drenou, inexoravelmente, o capital produtivo. Para que investir na indústria ou no comércio, numa expectativa de lucros a médio e a longo prazo, sujeitos a inúmeras contingências, quando, sem esforço, se pode obter um ganho muito superior e mais rápido, jogando com títulos ou puras realidades financeiras? Empresas saudáveis decidiram investir capitais em áreas mobiliárias fora do seu núcleo de negócios.
\end{abstract}

No Brasil, vieram à tona casos de duas grandes companhias, de sólida tradição na história da indústria nacional, que teriam investido grande soma de recursos nos chamados derivativos, operação que quase as levariam à falência. Trata-se do caso da Sadia e da Aracruz, que operavam no mercado financeiro com alta exposição a operações com derivativos, apostando na queda do dólar americano. A súbita desvalorização cambial trouxe fortes prejuízos a essas companhias. O caráter especulativo das operações, que em si não eram ilícitas, acabou, ainda que por anos tenha lhes dado lucro, rendendo a essas duas companhias grandes prejuízos, pegando de surpresa, por exemplo, seus próprios investidores, vez que são companhias listadas em bolsa, pois o foco em tais operações financeiras estava em desacordo com o próprio objeto da atividade empresária.

O caso dos derivativos, de toda forma, seria representativo da grande tendência de alteração da finalidade primordial das instituições financeiras, consistente no seu caráter instrumental, destinadas ao financiamento do setor produtivo. Nesse ponto, a perspectiva funcionalista apresentada no início do presente trabalho pode contribuir com seus meios, mediante a atuação transformadora do direito, capaz de criar estruturas com finalidade positiva, valendo de normas com sanções premiais ou de incentivos. O papel transformador da perspectiva funcionalista é assinalado por Bobbio (1977, p. 31):

È noto quale importanza abbiano per un`analisi funzionale della società le due categorie della conservazione e del mutamento. Considerando ora le misure di scoraggiamento e quelle d incoraggiamento da un punto di vista funzionale, il punto essenziale da rilevare è che le prime sono adoperate prevalentemente allo scopo della conservazione sociale, le seconde prevalentemente allo scopo del mutamento.

Assim, no momento atual da economia brasileira, marcado pelo protagonismo de bancos públicos de desenvolvimento, as críticas que a estes são dirigidas, em especial ao mais notório deles, o Banco Nacional de Desenvolvimento Econômico e Social (BNDES), a 
perspectiva funcionalista tem um campo de atuação propício. O BNDES, "principal instrumento de execução da política de investimento do Governo Federal" (art. 23, da Lei n. 4.595/64), pode ser entendido como uma estrutura jurídica cuja função legalmente atribuída é justamente o financiamento ao setor produtivo.

A novidade que a perspectiva da análise funcional pode agregar diz respeito à correção de desvios no manuseio deste instrumento, desvios estes que se viabilizariam justamente através de um instrumento jurídico fundamental na atividade financeira: o sigilo bancário, que ao invés de proteger a intimidade ou a privacidade como garantia fundamental que é, representaria uma grave disfuncionalidade ao ir de encontro ao princípio da transparência nos negócios públicos, o que prejudicaria o próprio desenvolvimento econômico nacional, para cuja promoção fora o Banco criado.

\section{O BNDES E O SIGILO BANCÁRIO}

Conforme disposto no art. $4^{\circ}$, do Decreto n. 4.418, de 2002, que aprovou o estatuto do BNDES, este exercerá suas atividades visando a estimular a iniciativa privada. Nos últimos anos, o referido banco de fato apoiou parte da iniciativa privada, o que está dentro de suas atribuições, conforme dispositivo estatutário antes referido, bem como da lógica econômica, na qual recursos limitados demandam escolhas. O grande questionamento diz respeito aos critérios pelos quais o Banco escolheu setores e agentes da iniciativa privada. Assim, por exemplo, operações de financiamento de alguns grupos empresariais, grandes doadores de campanhas eleitorais, como o grupo Friboi/JBS, ou o grupo empresarial do empresário Eike Batista, bem como o financiamento de obras de construtoras brasileiras em países como Venezuela e Cuba.

Outro fator que colocou esse banco no centro das atenções diz respeito ao papel que ele exerce no financiamento empresarial, ostentando nos últimos anos um considerável dispêndio de recursos. Com efeito, os financiamentos do BNDES são bancados pelo Tesouro Nacional, o que implicaria forte desestímulo à atuação dos Bancos privados, pois estes não conseguiriam competir com aquele banco público (TORRES FILHO; COSTA, 2012, p. 987). Ademais, é sempre lembrado o ônus para a sociedade brasileira gerado pelas operações deste banco de fomento, visto que seus recursos são captados à taxa de mercado, notadamente mediante emissão de títulos públicos remunerados pela taxa SELIC, enquanto seus 
financiamentos contam com remuneração significativamente menor, geralmente a taxa de juros de longo prazo (TJLP).

O envolvimento de grandes financiadores de campanha alimentou um clima de cobranças por parte da sociedade brasileira, que exigia conhecimento mais aprofundado das operações bancárias, desse agente. Pode-se, à vista destas circunstâncias, afirmar que o instituto do sigilo bancário trouxe disfuncionalidades no fomento público, à medida que a falta de transparência acentuou um recorrente vício da economia nacional, consistente nas relações espúrias entre o capital privado e o setor público, o chamado patrimonialismo.

Há relevantes estudos na literatura nacional sobre papel que Estado assume na delimitação da nossa economia, no perfil das nossas elites empresariais e na extensão da atividade econômica predominante em nosso país. No dizer de Faoro (2008, p. 81), dissertando sobre a formação do Estado brasileiro, este "organiza o comércio, incrementa a indústria, assegura a apropriação da terra, estabiliza preços, determina salários, tudo para o enriquecimento da nação e o proveito do grupo que a dirige". O patrimonialismo não se manifesta apenas no homem público, mas também no homem de negócios, pois na verdade tratar-se-ia de um só, inconsciente desta distinção entre esferas.

No Brasil, em geral, a empresa privada manteve uma relação promíscua com o Estado, na dependência de políticas públicas para se viabilizar, a exemplo de incentivoscreditícios e tributários ${ }^{3}$, quase sempre desenhados de forma pouco transparente, sem qualquer consulta à sociedade, sendo exemplar a situação do BNDES e a polêmica dos “campeões nacionais", pela qual o Poder Público e seu braço de fomento deliberadamente escolheram parceiros para serem vitaminados com dinheiro público sob condições e taxas de juros amigáveis, sendo o sigilo bancário um mecanismo jurídico cujo manuseio possibilitou essa apontada disfunção.

Pode-se dizer que houve uma atuação disfuncional do BNDES enquanto instituição de fomento, para qual o instituto do sigilo bancário em muito contribuiu, pois por meio deste se viabilizou transações bancárias desconhecidas da sociedade brasileira, comprometendo a persecução das finalidades institucionais do BNDES, notadamente, a busca pelo “desenvolvimento econômico e social do País".

Nesse passo, o BNDES foi instado a fornecer dados relativos a tais operações, ocasiões em que opôs o instituto do sigilo bancário. Calha detalhar essas ocasiões, as quais foram judicializadas em pelo menos três processos judiciais.

No processo n. 0020225-86.2011.4.02.5101 ${ }^{4}$, o Tribunal Regional Federal da $2^{\mathrm{a}}$ 
Região, sediado no Rio de Janeiro, no ano de 2013, julgou apelação em mandado de segurança proposto pelo Jornal Folha de São Paulo em desfavor do BNDES, pois este se negara a fornecer relatórios internos relativos a empréstimos feitos pelo banco entre 2008 e 2011. O tribunal atendeu ao pedido, em julgado ementado da seguinte forma:

MANDADO DE SEGURANÇA. ACESSO À IMPRENSA DE RELATÓRIOS DE
ANÁLISE ELABORADOS PELO BANCO NACIONAL DE
DESENVOLVIMENTO ECONOMICO E SOCIAL - BNDES. INEXISTÊNCIA
DE SIGILO BANCÁRIO. PRINCÍPIOS DA PUBLICIDADE E
TRANSPARÊNCIA.
É legítima a pretensão da imprensa de ter acesso a relatórios de análise, elaborados
pelo BNDES, contendo a justificativa técnica para as operações de empréstimo e
financiamentos milionários, concedidos com o emprego de verbas públicas (em
última análise). Matéria de interesse público indiscutível. Inexistem em tais
relatórios dados bancários sigilosos ou que comprometam a segurança da
sociedade e do Estado (art. $5^{\circ}$, incisos XIV e XXXIII, da Lei Maior). Observância
dos princípios da publicidade (art. 37 , caput, da CF) e da transparência, nos termos
da Lei n. ${ }^{\circ} 12.527 / 2011$. A própria essência da ideia republicana e a lógica da
liberdade de imprensa são respaldo suficiente a autorizar o acesso, aos canais
noticiosos, de dados importantes à ciência, pela população, do uso de vultosas
quantias de empresa pública de financiamento. Evita-se que se diga que favores
foram concedidos a amigos do rei. Apelação do BNDES e remessa necessária
desprovidas. Apelação dos Impetrantes provida.

Em 2014, no Processo $\mathrm{n}^{\circ}$ 0060410-24.2012.4.01.3400, da 20a Vara Federal do

Đistrito Federal ${ }^{5}$, foi proferida sentença julgando procedente ação civil pública proposta pela Ministério Público Federal em desfavor do BNDES, onde se julgou procedente o pedido para:

\begin{abstract}
Julgo procedente o pedido para condenar o réu na obrigação de fazer, consistente em tornar públicas, nos termos da Lei $\mathrm{n}^{\circ} 12527 / 2012$, todas as atividades de financiamento e apoio a programas, projetos, obras e serviços de entes públicos ou privados, que envolvam recursos públicos, realizadas por si ou por intermédio de outras pessoas jurídicas por ele instituídas, a exemplo da BNDESPAR, relativas aos últimos 10 anos, além das que vierem a ser realizadas doravante, discriminando-lhes os destinatários, a modalidade de apoio financeiro concedido e sua justificativa (empréstimo direto, empréstimo intermediado por terceiro, subscrição de valores mobiliários, entre outras), os montantes financeiros empregados, os prazos do investimento, o grau de risco do investimento, as taxas de juros empregadas, os valores de aquisição de ações, a forma de captação do recurso utilizado, as garantias exigidas, os critérios ou justificativas de indeferimento de eventuais pedidos de apoio financeiro, a compatibilidade do apoio concedido com as linhas de investimento do Banco), disponibilizando-as integralmente em seu sítio eletrônico, bem como para declarar a ilegalidade dada à interpretação ao disposto no art. $5^{\circ}, \S$
\end{abstract}

\footnotetext{
$3 \quad$ Nesse sentido, o importante trabalho de Lazzarini (2011).

4 Rel. Des. Federal Guilherme Couto de Castro, disponível em: http://www.trf2.gov.br/cgi-bin/pingresallen?proc $=201151010202257 \& \mathrm{mov}=1$.
} 
$1^{\circ}$, do Decreto $\mathrm{n}^{\mathrm{o}} 7.724 / 2012$, e condenar o réu na obrigação de repassar ao Ministério Público Federal as informações que lhe forem requisitadas, em procedimentos de suas competências, sobre operações de apoio e/ou financiamento (sob quaisquer modalidades), realizadas por si ou por sua subsidiária - a DBNDESPAR - a quaisquer entidades públicas ou privadas, sem que seja oposto a tais órgãos de controle o óbice do sigilo bancário, independentemente de ordem judicial.

Em 2015, o Supremo Tribunal Federal (STF) julgou mandado de segurança impetrado pelo BNDES contra ato do Tribunal de Contas da União (TCU). Conforme divulgado pela Corte, a Primeira Turma do STF negou o Mandado de Segurança n. 33340, impetrado pelo BNDES contra acórdão do TCU que determinou o envio, pela instituição financeira, de informações sobre operações de crédito realizadas com o grupo JBS/Friboi.

Por maioria, o colegiado seguiu o voto do ministro Luiz Fux, no entendimento de que o envio de informações ao TCU relativas a operações de crédito, originárias de recursos públicos, não é coberto pelo sigilo bancário e que o acesso a tais dados é imprescindível à atuação do TCU na fiscalização das atividades do BNDES.

Nesse processo, o Tribunal de Contas investigava justamente os critérios utilizados para a escolha da empresa beneficiada, as vantagens sociais advindas dessas operações, o cumprimento das cláusulas contratuais firmadas entre as partes, em especial dos termos referentes à aplicação de multas, a aquisição de debêntures e eventual prejuízo sofrido pelo banco com a troca dessas debêntures por posição acionária. O BNDES teria fornecido parte das informações requeridas, deixando de revelar o rating de crédito, o saldo das operações de crédito, a situação cadastral e a estratégia de hedge do Grupo JBS/Friboi, por entender que esses dados estariam sob a proteção do sigilo bancário e que as operações realizadas têm natureza de contrato de financiamento, estando, por isso, resguardadas pelo sigilo bancário.

O STF salientou que embora o sigilo bancário e empresarial sejam fundamentais para o livre exercício da atividade econômica e que a divulgação irresponsável de dados sigilosos pode expor um grupo econômico e até inviabilizar sua atuação, a preservação dos dados não pode ser vista como uma garantia absoluta. Nesse caso, inclusive, ter-se-ia a inviabilização da

\footnotetext{
5 Juíza Federal Adverci Rattes Mendes. Disponível em http://s.conjur.com.br/dl/decisao-justica-federaldf-sigilo-bndes.pdf.
} 
competência constitucional de um órgão pública de grande relevância institucional, o TCU. Mencionou-se ainda que as empresas que contratam com o BNDES devem saber que estão se relacionando com uma instituição pública, sujeita ao controle dos órgãos estatais. A questão da tipologia das instituições financeiras, inclusive, foi outro fundamento usado pelo Tribunal, pois o BNDES é um banco público de fomento econômico e social e não uma instituição financeira privada comum.

Nos três julgados se salientou a origem pública dos recursos financeiros do BNDES, invocando antiga jurisprudência que do STF que entendia ser inaplicável o sigilo bancário em se tratando de recursos dessa natureza. Por outro lado, o Banco limitou-se a alegar genericamente o sigilo, além de se tratar de uma instituição com personalidade jurídica de direito privado. Foram poucos os subsídios, em ambos os processos, para se aferir em que medida a não aplicação do sigilo bancário poderia afetar as operações do Banco.

Na discussão levada a cabo no STF, apenas o Min. Luís Roberto Barroso, que ao final restou vencido, ponderou pela necessidade de se distinguir, quando a não aplicação do sigilo bancário pudesse afetar empresas que figuram como contraparte nos financiamentos. Argumentou que, embora o interesse público no controle do destino dos recursos públicos deva prevalecer sobre o sigilo de forma geral, considera que parte das informações exigidas pelo TCU só poderiam ser entregues a partir de autorização judicial, sobretudo quando envolvam as informações sobre rating de crédito (classificação de risco produzida pelo banco com critérios próprios com base em documentos sigilosos e que poderiam comprometer a atuação da empresa em sua área) e estratégia de hedge, que poderiam impactar a credibilidade e a avaliação dos negócios.

A questão ganha maiores contornos, por exemplo, quando se observa o alcance do que foi discutido perante o Tribunal Regional Federal da $2^{\mathrm{a}}$ Região, em que se autorizou o acesso de empresa jornalista às informações bancárias, pois diferentemente dos outros casos, não se trata de instituição pública, como o Ministério Público e o Tribunal de Contas.

$\mathrm{Na}$ verdade, é sempre possível argumentar que os agentes privados que acorrem ao banco público de fomento têm conhecimento do caráter público de seus recursos, bem como do regime de informações abrangente de informações. Se parece claro que o sigilo bancário amplo acaba por proporcionar distorções em bancos de fomento público no que diz respeito à transparência de seus negócios, cabe ainda questionar se a sua abertura irrestrita não poderia levar a uma funcionalização negativa das instituições de fomento. 
Com efeito, retornando às lições de Bobbio (1977, p. 100-101), a chamada função negativa difere da disfuncionalidade, sendo esta uma patologia, enquanto aquela integra a fisiologia de uma instituição. Na sua obra, o autor defende que o direito admite não apenas uma função positiva, como também uma função negativa. Normalmente, se destaca o mal funcionamento (disfunção) de instituições contemporâneas, como o parlamento, que apresenta defeitos de funcionamento como a subserviência ao poder executivo. Coisa diversa, entretanto, é a constatação de uma função negativa, pois essa consiste no fato de que $o$ resultado obtido por determinada instituição ou norma jurídica é o contrário daquilo que se propõe (BOBBIO, 1977, p. 100), exemplificando o autor com o sistema carcerário que funciona na verdade como uma escola de delitos.

Desta forma, é de se cogitar se o amplo e irrestrito afastamento do sigilo bancário das operações do BNDES, como dos demais bancos de fomento público, não implicaria atribuirlhe função negativa. Com efeito, se a publicidade ampla puder comprometer a atuação empresarial, trazendo exemplificativamente problemas de ordem concorrencial para a empresa tomadora do financiamento, especialmente se essa empresa tiver competidores internacionais, o relacionamento comercial com BNDES terá como resultado desestímulo à iniciativa privada, em antítese com a teleologia expressamente declinada no art. $4^{\circ}$ do Estatuto da referida instituição financeira.

Após os processos judiciais acima historiados o BNDES publicou na internet amplo conjunto de dados sobre suas operações, detalhando financiamentos concedidos e seus beneficiados. Uma curiosa consequência no mercado foi que a partir das classificações de risco produzidas nessas operações o BNDES passou a ser considerado como uma informal agência de rating.

Lembre-se, aliás, que, embora opere com recursos públicos, o BNDES não deixa de ser banco, sendo curial que, em se tratando de banco, venha a calhar um mínimo de discrição, sobretudo quando se sabe que o sucesso de um mercado depende da posição estratégica que as suas empresas assumem. Do contrário, seria o caso de se pensar na própria conveniência de se manter tal incentivo, isto é, se o melhor não seria a extinção dos bancos públicos de fomento, e o adequado estímulo, por exemplo, aos bancos privados de financiamento, ou mesmo concentrar esforços no desenvolvimento do mercado de capitais. 


\section{CONCLUSÕES}

A predominância do sistema financeiro sobre o sistema econômico é uma observação quase consensual entre os estudiosos em geral. As instituições financeiras adquiram um status de grandes proporções, sendo uma realidade o protagonismo econômico, social e político de grandes bancas, cuja grandeza compromete a própria sobrevivência do sistema financeiro (too big to fail).

Esse protagonismo irrompeu um descasamento de instituições financeiras ao seu clássico propósito, consistente no financiamento do setor produtivo. No Brasil, o recurso a instituições legalmente desenhadas para essa finalidade apresentou sérios problemas, relacionados à falta de transparência e questionamentos quanto à eficiência das operações conduzidas pelo maior banco de fomento do país.

O sigilo bancário pode ser apontado como fator potencializador da veia patrimonialista que caracteriza os negócios privados, conduzidos à sombra do Estado.

Por outro lado, os avanços hauridos em sede judicial, em prol da transparência em negócios em que haja participação do BNDES, podem, se levados ao limite, implicar efeitos contrários ao que institucionalmente o referido banco se propõe, especialmente se adotado uma excessiva ampliação da publicidade de tais negociações.

\section{REFERÊNCIAS}

ABRÃO, Nelson. Direito bancário. São Paulo: Saraiva, 2000.

ASCARELLI, Tullio. Panorama do direito comercial. Sorocaba: Editora Minelli, 2007.

BACHA, Edmar; ARIDA, Pérsio; REZENDE, André Lara. Crédito, juros e incerteza jurisdicional: conjeturas sobre o caso Brasil. In. BACHA, Edmar. Belíndia 2.0: fábulas e ensaios sobre o país dos contrastes. Rio de janeiro: Civilização Brasileira, 2012.

BOBBIO, Norberto. Dalla struttura alla funzione - nuovi studi di teoria del diritto. Milão: Edizioni di Comunità, 1977.

BRASIL. Lei $\mathrm{n}^{\mathrm{o}}$ 4.595, de 31 de dezembro de 1964. Dispõe sobre a Política e as Instituições Monetárias, Bancárias e Creditícias, Cria o Conselho Monetário Nacional e dá outras providências. Diário Oficial [da] República Federativa do Brasil, Brasília, DF, 31 dez. 1964. Disponível em:

<http://www.in.gov.br>.Acesso em: 16.07.2015. 
CARVALHO, Nelson Marinho de. Evidenciação de derivativos. Cad. estud., São Paulo , n. 20, p. 01-16, Apr.1999 Available from

$<$ http://www.scielo.br/scielo.php?script=sci_arttext\&pid=S141392511999000100003\&lng=en $\& n r m=i$ so $>$ access on 15 June 2015. http://dx.doi.org/10.1590/S141392511999000100003.

CORDEIRO, Antonio Menezes. Direito bancário. Coimbra: Almedina 2014.

DELFIN NETO, Antonio. O futuro está mais opaco do que costumava ser. Valor Econômico, São Paulo, 30 jun. 2015. Brasil, p. A2.

FARIA, José Eduardo. Poucas certezas e muitas dúvidas: o direito depois da crise financeira.

Revista DIREITO GV São Paulo: DIREITO GV, v. 5, n. 2, jul-dez 2009, pp.297-324.

FORGIONI, Paula A. A evolução do direito comercial brasileiro: Da mercancia ao mercado. 2a . ed. São Paulo: Editora Revista dos Tribunais, 2012.

Contrato de distribuição. $2^{\text {a }}$.ed. São Paulo: Editora Revista dos Tribunais,

2008. GALGANO, Francesco. Lex mercatoria. Bolonha, Il mulino, 2010

LAZZARINI, Sergio G. Capitalismo de laços: os donos do Brasil e suas conexões. São Paulo: Campus, 2011.

LE GOFF, Jacques. Mercadores e banqueiros da idade média. São Paulo: Martins Fontes, 1991. METRI, Mauricio. Poder, riqueza e moeda na Europa Medieval: a preeminência naval, mercantil e monetária da sereníssima República de Veneza nos séculos XIII e XV. Rio de Janeiro: FGV Editora,

2014.

MACE,Y Jonathan R. The Business of Banking: Before and After Gramm-Leach-Bliley, 25 Journal of Corporation Law 691 (2000).

OECD. Finance and Inclusive Growth. OECD Economic Policy Paper, june 2015 no. 14. Genebra,2013. Disponível em: < http://www.oecdilibrary.org/docserver/download/5js06pbhf28s.pdf?expires $=1435932538 \&$ id=id\&accname $=\mathrm{gu}$ est\&che cksum=4F041B0439976C04C43AB4FBD3ABFD84>. Acesso em: 20 jun. 2015.

NUNES, António José Avelãs Nunes. A crise atual do capitalismo: capital financeiro, neoliberalismo, globalização. São Paulo: Editora Revista dos Tribunais, 2012.

PINHEIRO, Armando Castelar; SẢDDI, Jairo. Direito, economia e mercados. Rio de Janeiro, Elsevier, 2005.

SALOMÃO NETO, Eduardo. Direito bancário. São Paulo: Atlas, 2011.

SZTAJN, Rachel. Sistema financeiro: entre estabilidade e risco. Rio de Janeiro: Elsevier, 2011. 
TORRES FILHO, Ernani Teixeira; COSTA, Fernando Nogueira da. BNDES e o financiamento do desenvolvimento. Economia e Sociedade, Campinas, v. 21, Número Especial, p. 975-1009, dez. 2012.

VERÇOSA, Haroldo M. D. Contratos mercantis e teoria geral dos contratos. São Paulo: Quartier Latin, 2010. 